\title{
Perception of Architecture Students on Factors Influencing the Selection of Locations for Academic Trip and Site Visit
}

\author{
Wardah Fatimah Mohammad Yusoff ${ }^{1^{*}}$, Nor Haslina Ja'afar ${ }^{2}$ \& Noraziah \\ Mohammad $^{3}$
}

${ }^{1,2,3}$ Centre for Innovative Architecture and Built Environment, Faculty of Engineering and Built Environment, Universiti Kebangsaan Malaysia, 43600, Bangi, Selangor, MALAYSIA.

DOI: https://doi.org/10.30880/jtet.2019.11.03.004

Received $10^{\text {th }}$ March 2019; Accepted 22 ${ }^{\text {nd }}$ July 2019; Available online 30 ${ }^{\text {th }}$ September 2019

\begin{abstract}
One of the approaches in the architectural design studio pedagogy is an academic trip, in which it is always associated with a site visit. This approach is widely applied in architectural education around the world. However, there are challenges in executing this approach. Thus, this study aims to identify the students' perceptions of the academic trip and site visit via factors that influence the trip location. A mixed-method approach was applied, where it involved 32 questionnaire surveys and 20 in-depth interviews. The final year Bachelor of Science in Architecture students of Universiti Kebangsaan Malaysia were selected as respondents. The quantitative data from the survey had been analyzed using simple statistic such as percentage and frequency. However, the qualitative data gained from the in-depth interview was analyzed using thematic analysis. The findings indicate that the students opine that the visit is beneficial for them. However, most of them also agree that the factors of travelling time, financial and knowledge exposure affect their choices for the location. The findings also demonstrate that the students still opt for farther academic trip and site visit location though they face financial issues. Hence, it is recommended that further action should be taken such as the provision of financial support to encourage the academic trip and site visit as the architectural design studio pedagogies. Farther location of the visit provides more exposure to the students. This helps to produce graduate architects that are more sensitive towards the diversity of culture, heritage and built environment.
\end{abstract}

Keywords: Architectural design studio, architecture students, perception, academic trip, site visit

\section{Introduction}

Technical and vocational education and training (TVET) in Malaysia is offered at various levels such as certificate, diploma and degree. It focuses in providing knowledge and skills related to the technologies and sciences, in order to prepare the graduates for the industry. One of the fields in TVET is architecture, which it can be pursued at many levels such as certificate, diploma and degree. Examples of community colleges that offer the architectural technology certificate are Arau Community College and Tapah Community College. Meanwhile, the architecture diploma is offered by various polytechnics and higher institutions such as Port Dickson Polytechnic, Tunku Abdul Rahman Universiti College and Infrastructure University Kuala Lumpur. After the diploma level, the students may pursue to the degree level. One of the higher institutions in Malaysia that offers the architecture degree is Universiti Kebangsaan Malaysia.

Architectural education is a complex process as it demands high creativity with the support of knowledge from various fields. Besides creativity, the learning of architecture involves knowledge and skills that are cumulative and progressive. The TVET programme related to architecture is very useful in preparing the students for the industry. This is because besides knowing how to design buildings, the students must also possess knowledge and skills related to the technical and construction as well as the current computer technologies used in the industry. The creativity, together with the sufficient knowledge and skills will produce an architectural graduate that is competent for the industry. 
The core subject for the architecture programme is design studio, where it involves groups of students guided by a studio master or instructor (Kurt, 2009; Sawyer, 2017). In Universiti Kebangsaan Malaysia (UKM)'s architecture programme, the design studio takes about six to eight credit hours per week, in which this is a normal practice for other architecture schools in Malaysia. The high credit hours compared to the normal two to three credit hours per week for other subjects has indicated on the importance of design studio in producing a competent graduate architect. In the Manual of Accreditation for Architecture Programme (Board of Architects Malaysia, 2013), design studio is referred as a studentcentered educational pedagogy which applies project-based problems. This approach requires students to identify the problems or issues, analyse them, and develop creative techniques or methods to solve them. It is an active learning process that involves either group or individual works, thus encouraging the development of many other skills such as leadership and communication.

The architectural design studio pedagogy does not involve the conventional method only, where the students listen to the lecture. There are many other activities involved such as discussion, precedent studies, desk-crit (where it comprises one-to-one project critique), project presentation and seminar, peer critique and evaluation, portfolio review and exhibitions as well as off-studio activities such as academic trip and site visit (Board of Architects Malaysia, 2013). These activities may occur within a dedicated space for studio or in other places such as laboratory, gallery, as well as outdoor area. With these various approaches, students get the opportunity to develop many skills such as evaluation skill, graphic and verbal presentation skills, observation skill and communication skill.

\section{Academic Trip and Site Visit}

There are many ways of conducting academic trip and site visit. However, having an effective and meaningful field trip is a challenge as it has to be well-managed, provides motivational experience and becomes an effective learning tool (McLoughlin, 2004). The effective methods depend on many factors such as the objective or purpose of the trip, the participant numbers, the duration and many more. Leydon and Turner (2013) had organized a field trip for a large number of university students which were more than one hundred. To ensure the effectiveness of the trip, the practical sessions were introduced prior to the actual field trip. The practical sessions, which were executed within the campus, involved the theories and techniques used in the field trip. These practical sessions were very beneficial as they reduced the onsite instructions during the actual field trip. In addition, the large number of students were also divided into many groups, with one teaching assistant for each group. Meanwhile, McLoughlin (2004), Coughlin (2010) and Scott and Matthews (2011) had suggested three sessions namely the pre-field trip, the actual field trip and the post-field trip in ensuring the effectiveness of the trip. In addition, Coughlin (2010) also suggested on having a collaboration between the stakeholders in organizing the field trip to make it more effective and meaningful. An effective field trip also requires active involvement of the teachers or facilitators prior to the trip. The teachers need to do homework regarding the location of the trip, such as the on-site facilities, the logistical information and many more. It is also recommended that the teachers visit the site themselves before bringing the students (McLoughlin, 2004).

As mentioned before, the architectural design studio pedagogy also involves the off-studio activities such as academic trip and site visit. Though these two activities encompass trip or visit to another place or location, there are differences in the purpose of the activity. The site visit involves a trip to a chosen site which will be used in the studio project. During the site visit, the students are required to conduct the site analysis, where they have to investigate thoroughly all aspects related to the site such as the site condition and physical features, the demography and culture of surrounding populations, the neighborhood context, the historical and environmental aspects and many others. On the other hand, the academic trip encompasses a visit to certain places with the purpose of exposing the students to the experience and knowledge related to the field of study.

In the architectural education, the academic trip and site visit can be conducted in separation or combination, depending on the situation and requirement of the project. In some situation, the academic trip which the students visit buildings or places for case studies, may also involve site visit if the site is located nearby. However, if the case studies are located far from the selected site, the visit or trip might be held separately. Both approaches have their own advantages and drawbacks. The former approach may save more time and cost compared to the latter approach. However, the drawback of the former approach is that if the site is located far from the institution, the students may face problem of revisiting it. In some situations, the students may need to revisit the site to do more observation or collect more data.

In architecture, the students are also learning from the nature and built environment. In other words, the surrounding is like a living classroom for them to learn and gain knowledge. This is because architecture is not solely related to the physical building design, but it also involves the incorporation of other fields, systems and values such as sustainability, technology, community, culture and tradition (Ibrahim \& Utaberta, 2012; Keumala et al., 2016). The buildings designed by the students are meant for various functions and users, with various background, capabilities and necessities. Therefore, the knowledge required by the students is unlimited to certain group of people, places and time. For example, the buildings designed for current used may need to be adapted to other usage in the future. Hence, the students have to employ the concept of flexibility and adaptability in the building design.

As architecture requires high creativity, it is essential for the students to possess it in providing solutions to the issues and problem. The creativity, which is supported by the theoretical knowledge, may produce effective solutions. However, there are students who are not capable of interpreting the theoretical knowledge that they have learnt into 
practice. The norm of education from school to university that emphasizes on memorization is one of the factors that contributes to this incapability (Danaci, 2015). Nevertheless, experiencing a situation or an environment via academic trip or site visit is able to enhance this capability. Lacking of personal experience will limit the students' capabilities of understanding and visualizing spaces. Personal experience is essential for the students to understand the architectural elements such as light, form, texture, scale, proportion and many more. With this personal experience, students can also understand the environmental, cultural and social aspects around them (Abdullah, Beh, Tahir, Che Ani, \& Tawil, 2011; Keumala et al., 2016).

The academic trip and site visit are among the pedagogies that should remain important as they provide direct experience to the students (Hope, 2009; Sawyer, 2017). These activities allow the students to observe and understand the real condition, issues and problem of buildings. Normally, the buildings selected for the case studies of the academic trip are related to the studio project. By visiting the case studies, students can observe and understand in real-life the functions and operation, the spatial arrangement and connection, the construction and services as well as the human behaviour within the buildings.

Besides academic trip, site visit is also essential as it is also able to provide personal experience to the students. It is one of the important steps in design process as the buildings designed by the students will be located at a specific site. During the visit, students will execute site analysis that encompasses all the issues and information related to the site and its surrounding. By experiencing the real situation of the site as well as understanding the site condition and its uniqueness, the proposed design and solution will be more appropriate and fruitful. The study by Mahdavinejad, Shahrigharahkoshan, and Ghasempourabadi (2012) and also Sawyer (2017) indicated that students who spend more time on site analysis will produce more functional and creative design. In this case, by having deep understanding of the site, as well as its issues and problem, students are able to provide new solutions that have better response.

The academic trip and site visit organized by UKM architecture programme normally involve three stages, which are: 1) the pre-trip, 2) the trip and 3) the post-trip. Though this approach is similar to the one suggested by previous studies, there is additional strategy employed by the architecture programme of UKM. The additional strategy is the active involvement of the students prior to the trip. The objectives for the academic trip or site visit are usually outlined by the lecturers at the pre-trip stage. These objectives are made known to the students, so that they are aware of the purpose of the visit, hence making full preparation that is necessary in achieving those objectives. Though the objectives have been outlined, they could be changed or extended during the visit, depending on the interaction with the surrounding situation (Nishio \& Kashihara, 2016).

The active involvement of the students starts during the pre-trip stage. Though the objectives are determined by the lecturers, majority of the trip preparation is conducted by the students. They have to form an organizing committee which encompasses the leader, the secretary, the treasurer and other committees such as transportation, accommodation and many more. With the guide from the lecturers, they learn all the process and procedures in making the trip successful. They even involve in the preparation of the trip activities with the lecturers. During the trip, the students have to follow the itinerary and activities that have been planned prior to visit. They have to take photos and document all the information and knowledge gained during the visit. These information, knowledge and experience derived during the visit will then be presented at the post-trip stage. All the activities occurred during the pre-trip, trip and post-trip provide abundant benefits to the students. The purposes of the active involvement of the students, starting from the pre-trip, are to provide opportunity for the students to learn methods and procedures of organizing a trip, as well as developing soft-skills for the students such as leadership, communication and teamwork.

According to Demirkaya and Atayeter (2011) and also Sawyer (2017), the interview conducted with the students after the field trip indicated that the students' interest and understanding on the subject matter rise, and the knowledge gained is hardly forgotten. Moreover, the field trip has also strengthened the relationship between the lecturers and students, compared to the classroom situation where the relationship is more formal. In the architecture academic trip, the usual expenditures involve the transportation, accommodation and food. However, if the case studies require entry fees, the students may need to allocate extra money for entering them. Reduction of expenditure may occur if the trip or visit is conducted at places located near the institution as the accommodation cost can be omitted. Moreover, the UKM's regulation has outlined that the students may use the institution's transportation such as bus and coach for free if it is just a daily trip, where it does not involve extra working hours for the driver.

It is undeniable that academic trip and site visit are very beneficial, and they are also among the effective educational pedagogies in exposing the students to the real-life situation. However, due to various family background, the students may face different issues regarding to the academic trip and site visit. Some students may afford a trip that cost high expenditure, while there are also students who have very limited budget. Hence, this study is executed to identify the students' perceptions of the academic trip and site visit via factors that influence the trip location. The findings of the study are beneficial to the institution and lecturers as guidance in organizing the academic trip and site visit for the students.

\section{Methodology}

A mixed-method research approach was employed in this study, where the case study involved the final year students of architecture programme at UKM. This study utilized two main techniques for data collection, namely the 
questionnaire survey and the in-depth interview. These techniques involved the analyses of quantitative and qualitative data. The quantitative data was derived from the questionnaire survey, while the qualitative data was obtained from the in-depth interview.

The combination of both techniques which are the questionnaire survey and in-depth interview, is able to provide valid and strong results, as each technique has its strengths and weaknesses. Therefore, having these two techniques will counter balance each other. The rich data will generate more reliable results via triangulation of the data techniques. This is due to the nature of quantitative data that concludes generally through a number of results from a population sample. However, it could not explain in detail towards the issues encountered. On the other hand, an in-depth interview with qualitative in nature has an advantage in term of describing data in detail, which is more meaningful (Creswell, 2014; Creswell \& Creswell, 2018).

This type of approach is appropriate because this study is an exploratory research. In this study, the qualitative data obtained from the in-depth interview manages to support and answer in detail the quantitative data derived from the questionnaire survey. According to Creswell (2014) and also Creswell and Creswell (2018), there are various types of mixed study approaches, in which this study adopted a 'concurrent design' where both qualitative and quantitative data were collected concurrently. The mixed mode occurred during the discussion and analysis prior to the determination of the final results.

This study applied case study as research strategy, where the architecture programme of UKM was chosen in this study due to the recognition as among the world's top universities for architecture \& built environment by the QS World University Rankings 2018. The sampling design used in this study was a non-probability sampling. All the final year students of Bachelor of Science in Architecture, UKM were selected as respondents of this study. Their number was small which were 32 students only. This group of students (final year) was selected as they had experienced various locations for the academic trips and site visits, either near or far from the institution. UKM, the institution where the students were studied are located in Bandar Baru Bangi, Selangor, which is within the Klang Valley area.

During their first year of architecture study, the students were brought to Kelantan and Terengganu, which are located more than $400 \mathrm{~km}$ from their institution. Meanwhile, in their second year of study, the academic trip was held in Singapore, which is the neighbouring country of Malaysia. They revisited Terengganu during the first semester of their third year study for the community centre studio project. (Fig. 1). Meanwhile, for the second semester, the selected site was located in Bandar Baru Bangi, which is just about $5 \mathrm{~km}$ from UKM. The studio project during the second semester was to design a serviced apartment, in which for this project, the students had conducted visits to the serviced apartment buildings within the Klang Valley. This shows that the final year student is the most appropriate sample to be taken compared to other years because all the trips and visits were executed in different semesters, and to serve different types of studio projects.
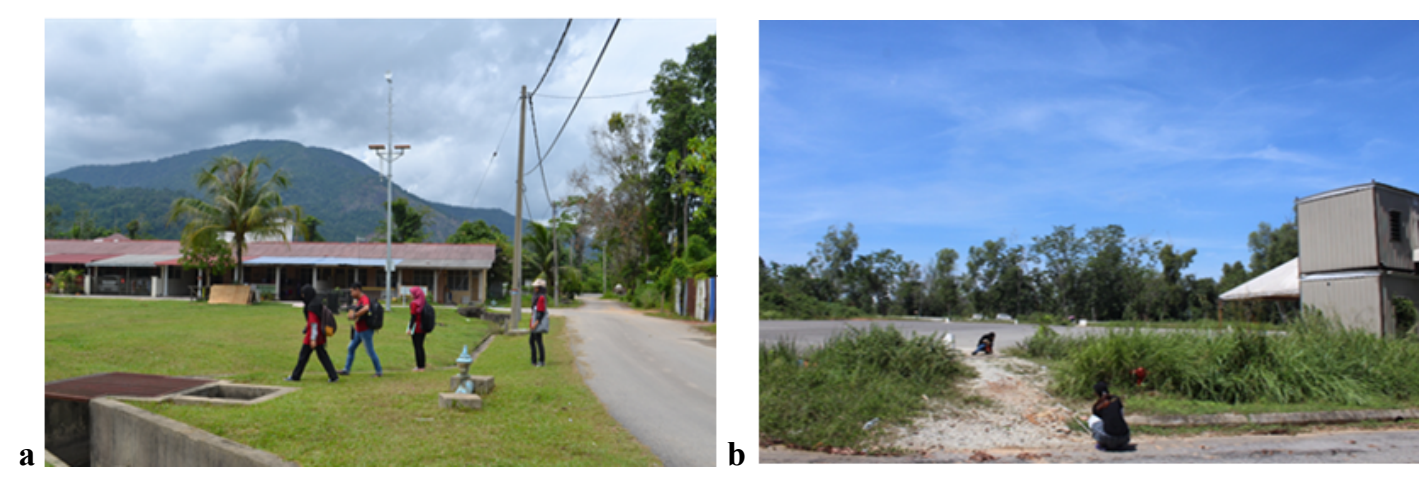

Fig. 1 - (a) The students conducted site analysis during the site visit in Besut, Terengganu; (b) and Bandar Baru Bangi, Selangor

As mentioned in the research approach, this study utilized two techniques, which were the questionnaire survey and the in-depth interview. For the questionnaire survey, all the 32 students were selected as the respondents, with $100 \%$ confidence level since their number was small. This study received 100\% (32 respondents) feedback from the students. The survey required 10 to 15 minutes per respondent to answer all the questions. The questionnaire involved a structured questionnaire design to obtain quantitative data. It encompassed four main sections, namely; (i) Socio-demographic, (ii) The choice of location, (iii) Factors for choosing the location, and (iv) Open-ended questions.

The second section of the questionnaire involved a 'dichotomous' or 'close-ended' question, which required the answer of 'yes/no'. For information, the selected institution, which is Universiti Kebangsaan Malaysia (UKM), is located within the Klang Valley area. Therefore, in the questionnaire survey, the locations for the academic trips and site visits were classified into two, namely (i) outside the Klang Valley, and (ii) inside the Klang Valley. However, the third section involved the scaling questionnaire, using 4-Likert scale namely very disagree, disagree, agree and very agree. This scale was chosen because according to the pilot study results, majority of the students preferred to answer 'neutral' when 5- 
Likert scale was utilized. Such answer pattern definitely affected the outcome of the study. Therefore, the 4-Likert scale was employed where this type of design will not allow any fence sitter to select a neutral option. This 4-Likert scale seems an appropriate scale to answer the objective of this study as suggested by Joshi, Kale, Chandel and Pal (2015). In the third section, there were three items listed as the factors, which were the travelling duration, the travelling cost, and the knowledge exposure. The quantitative data was analyzed statistically using frequency and percentage, where the Microsoft Excel software was employed. Meanwhile, the last section encompassed an open-ended question where a space was provided in the survey form for the students to add any other factors that in their opinion would influence the selection of site location.

Besides the questionnaire survey, this study also employed an in-depth interview. The interview was conducted with the purpose of obtaining more detail information for the data derived from the questionnaire survey. The in-depth interview technique is essential as it is able to provide detail and comprehensive data that is necessary (Uzairiah, 2016). The technique was conducted with 20 respondents as sampling size. The small number of respondents is already appropriate to obtain the qualitative data. According to previous scholars, if the in-depth interview is supported by a questionnaire method, the range of sampling size, which is between 20 to 40 respondents, is acceptable (Jaafar \& Harun, 2018; Alamoush, Jaafar, Husini \& Ismail, 2018). This shows that the 20 respondents sample is the appropriate sampling size for this study because it is within the suggested range by the scholars. Moreover, the study by Jaafar and Harun (2018) also used 20 respondents sample for their mixed method approach.

The respondents had been questioned in detail on the reasons that led to their choices of site location. This study utilized a semi-structured interview due to the recommendation by the previous study which stated that this type of approach is suitable for exploratory research (Alamoush et al., 2018). During the interview session, a lot of additional questions were asked also in deriving more detail and extended explanation. Tools like recording tape, pen and paper were used during the interview session. The derived data was analysed thematically according to the framework of this study.

\section{Results and Discussion}

The results of questionnaire survey were analysed using excel programme. Out of 32 students who involved in this survey, $69 \%$ chose to have site location outside the Klang Valley, while the other $31 \%$ chose for a site within the Klang Valley (Fig. 2). Their choices might be influenced by many factors. However, in this study, only three factors were listed, where the students had to choose to agree or disagree with the factors. Nevertheless, in the survey form, there was also a space provided for the students to state any other factors that influence their choice.

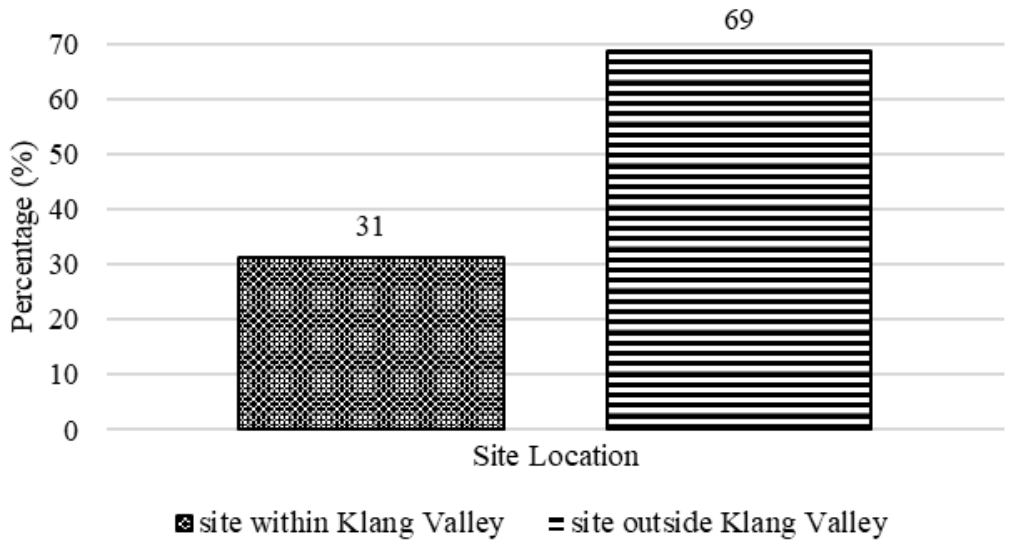

Fig. 2 - Project site location within and outside the Klang Valley

With regard to the factors that influence the choice of the students, the findings show that most students agreed that the travelling duration and cost as well as knowledge exposure affect their choice of site location. $66 \%$ of the students agreed and very agreed that the travelling duration influences their choice (Fig. 4). However, by associating the results of Fig. 4 with Fig. 3, the findings indicate that the students seem not to bother the extra journey duration they have to spend for a site that is located far from the institution. This is in corresponding with the findings from the results of Fig. 4, which show that though the students admitted that the travelling cost influences their preferred site location, $78 \%$ (agree and very agree) of them still choose to have a site outside the Klang Valley.

In addition, by comparing the results in Figs. 3, 4 and 5, the findings show that among the three factors listed in the questionnaire, the knowledge exposure factor seems to be the most influencing factor that determine the students' choices for the site location. $97 \%$ of the students agreed and very agreed on the influence of knowledge expose factor, while only $3 \%$ of the students very disagreed. This is in accordance with the studies by Abdullah et al. (2011) and Hope (2009) 
which stated that the personal or direct experience is essential in helping the students to understand many aspects around them. In this study, the personal experience is obtained via participating in the academic trip and site visit. With the personal experience, the students' knowledge and understanding of certain aspects and issues increase. The second factor that influences their choice is the travelling cost, while the travelling duration is the least influencing factor to them. Besides that, the findings in Figs. 3, 4 and 5 also indicate that there are students who have no concern on these factors in choosing their preferred site location. Moreover, there is also a student who had listed other influencing factor, which is the site quality.

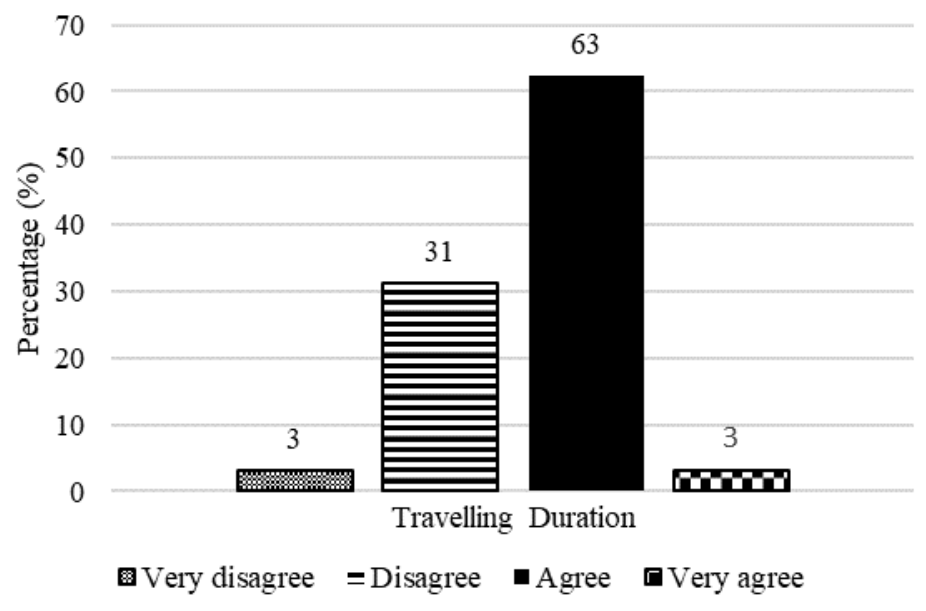

Fig. 3 - Factor of travelling duration.

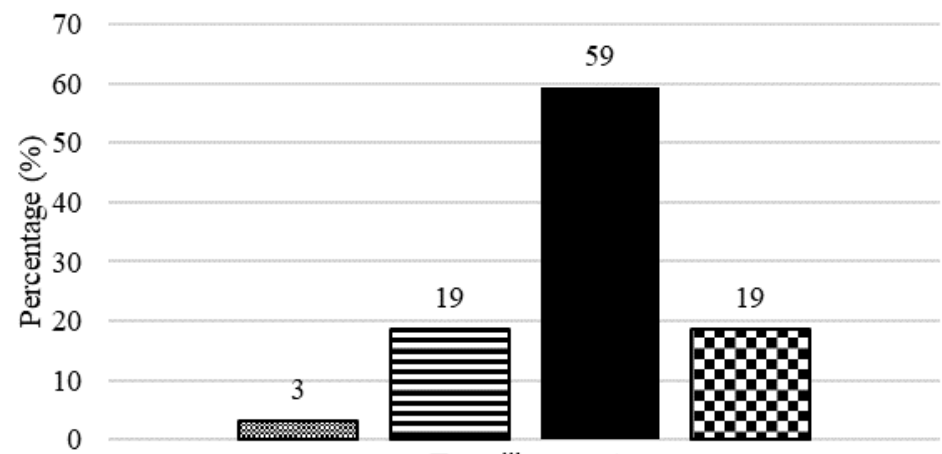

Travelling cost

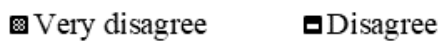

Fig. 4 - Factor of travelling cost.

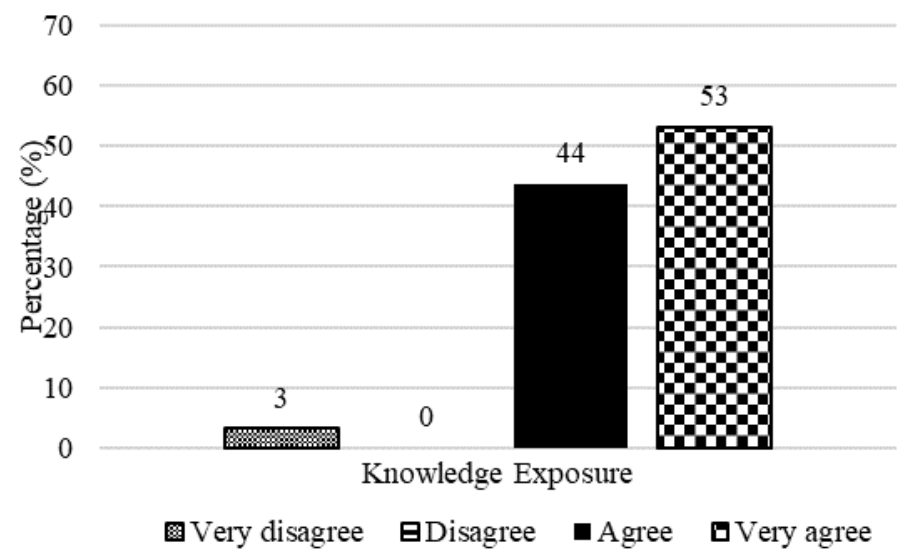

Fig. 5 - Factor of knowledge exposure. 
The findings from the questionnaire survey show that knowledge exposure becomes the main factor that influences the students' choice for the site location. The findings have been elaborated in detail via the in-depth interview with the students, as shown in the quotation below:

"I prefer the site located outside the Klang Valley because I learn new things, which open my mind. While I was in the first year, the visit to Terengganu provided opportunity for me to learn carving at Mr. Norhaiza's (the sculptor) house. When he gave talk, I realized that a carving is not merely an object but soul is also needed inside it. Carving and 'keris' are important because they are our heritage and identity" (Respondent 1)

"I also experienced the environment of fisherman village while visiting Terengganu. Their daily life and culture are different from us. I felt the ambience of village life that has strong community, and the people there are also friendly. We are from the city, and though they didn't know us, they still welcome us. They are hardworking and always be at the jetty. If it is not a fishing season, they will fix the net. I like the smell and sound of the sea, and I felt calm when I was there. Now I know how the fishermen live.” (Respondent 2)

"I like Mr. Norhaiza's traditional house which is built on stilt. I experienced myself the house's spaces. It was really interesting as I live in a terrace house, which has different environment. I also enjoyed carving at the space underneath the house." (Respondent 3)

The quotations above indicate the students' experience while visiting Terengganu and Kelantan, the East Coast of Peninsular Malaysia. The visit exposed the students to the new culture and community way of living that are related to the Malaysian heritage (Fig. 6). The students learnt to carve and the philosophical of carving from Mr Norhaiza, who is a sculptor. Moreover, they also learnt about traditional Malay Terengganu houses by exploring themselves the modular of houses which belong to Mr Norhaiza. They learnt about carving and the philosophy of wood and 'keris' via Mr Norhaiza's input talk that was held at the space underneath 'rumah ibu'. During the interview, all respondents mentioned that it was their first time experience of carving. Besides carving, the students also experienced the environment of fisherman village and the culture there. They also felt the strong sense of community and place via the village setting. Moreover, the smell of fish and the sound of sea also contribute to the tranquil surrounding and environment.
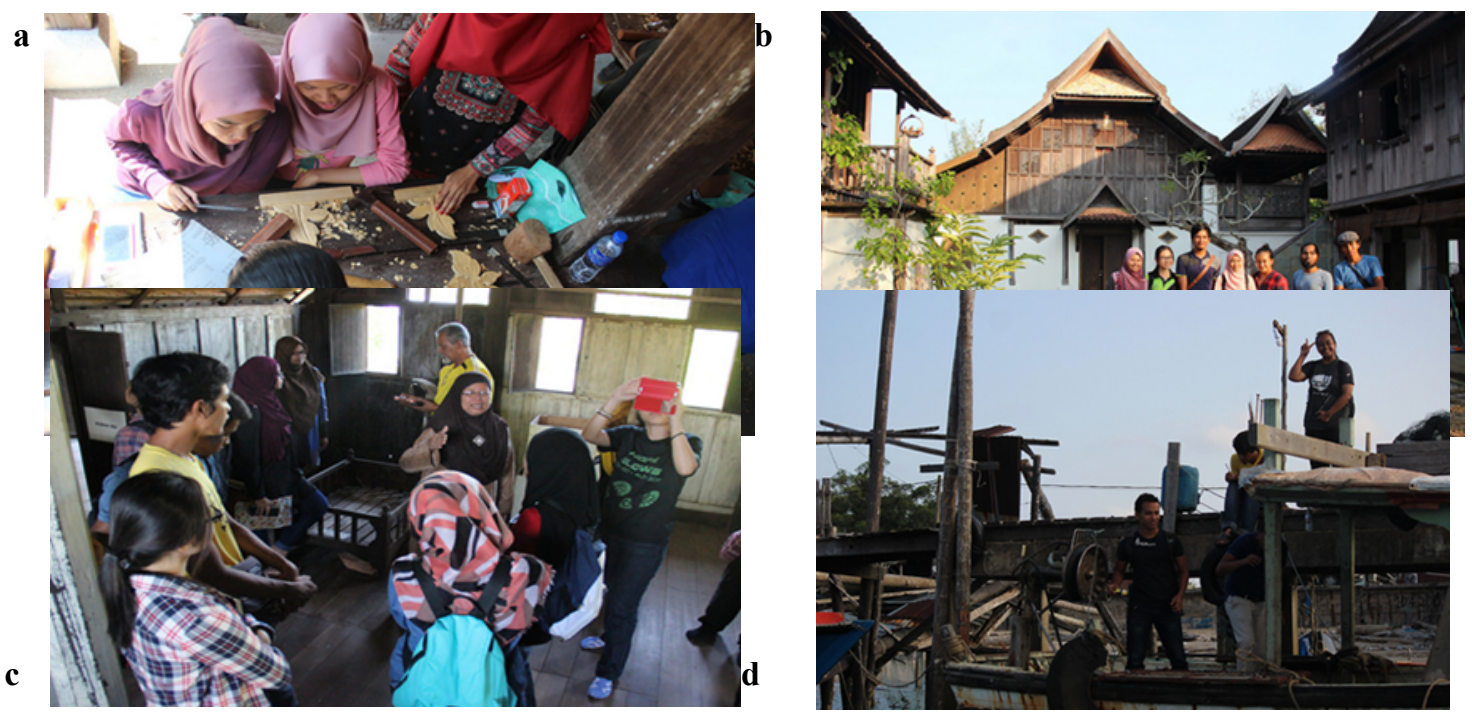

Fig. 6 The students' visit to Kelantan and Terengganu, where (a) the experience of wood carving activity at the space underneath 'rumah ibu'; (b) the ambience of Terengganu Traditional Malay House that belongs to Mr Norhaiza; (c) the input talk regarding 'keris' and Malay culture; (d) the experience of fisherman village gained by the students

The data collected via the in-depth interview indicates that the academic trip to Kelantan and Terengganu was very fruitful and beneficial as the students managed to gain a lot of knowledge and experience especially related to the culture of people in the East Coast of Peninsular Malaysia. In addition, the students also shared their experience of visiting Singapore (Fig. 7) during the interview, as the quotations below:

"I learnt a lot of new things, which open my mind. Architectural characteristics in Singapore are more modern compared to Malaysia. However, they are lacking in the heritage part. In my opinion we should preserve our heritage culture and buildings." (Respondent 1)

"Singapore has good facilities of public transportation. Therefore, most of the people utilize public transportation rather than driving their own vehicles. The whole country is clean, even the public toilet." (Respondent 3 )

From the interview, it shows that the academic trip to Singapore provided different experience compared to their trip to the East Coast of Peninsular Malaysia. The visit to Singapore exposed the students to the modern architecture style, as well as the urban culture. They also learnt the walkability characteristic of an urban area. The experience gained 
during the visit made them acknowledged that the clean environment and good public transportation facilities are essential in encouraging people to walk. In addition, they also learnt that heritage is important in reflecting one's identity, which this aspect is lacking in Singapore. This has made them realize on the importance of conserving the tangible (eg, building) and intangible part (eg, cultural) of Malaysian heritage.

Besides providing new knowledge and experience, these two academic trips also manage to inculcate the awareness of national identity architecture to the students, which this is the aim of UKM's Architecture Department. This is also parallel with the efforts conducted by the Board of Architects Malaysia (LAM) in promoting the awareness towards the national identity architecture. For example, LAM has outlined that the identity of a place can be appreciated via the language, music, food, nature elements, urban form and architecture. Architecture is not merely about buildings, but it can also portray effectively the aspects of culture and national patriotism, as well as the spirit of a place (Board of Architects Malaysia, 2017). In addition, UKM's Architecture Department has emphasized that the national identity architecture encompasses four main components namely community, sustainability, heritage, as well as codes and ethics.
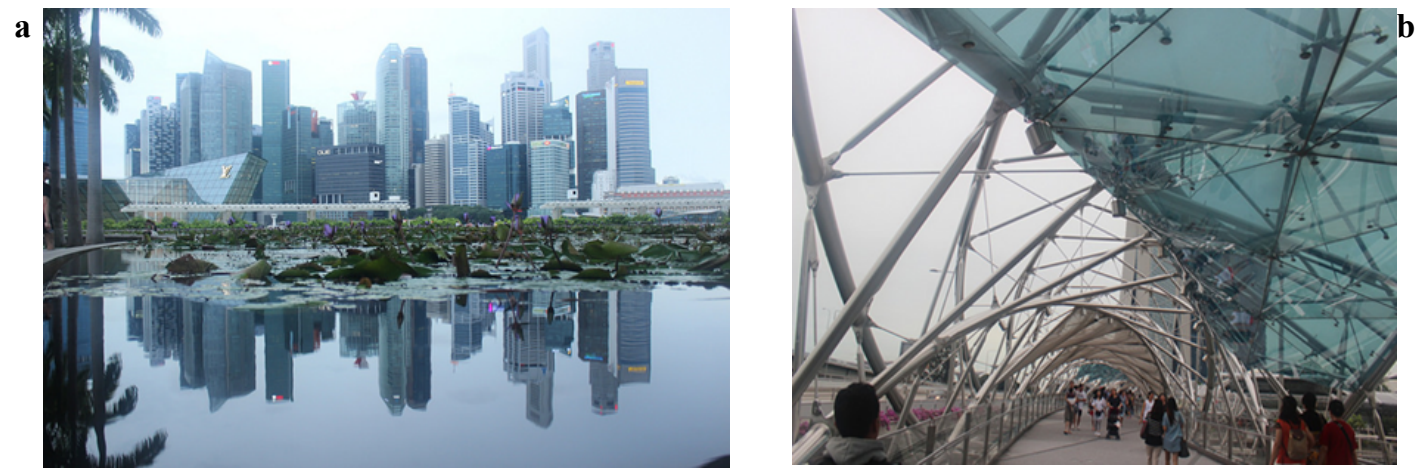

Fig. 7 - The students' visit to Singapore, where (a) the experience of Singapore urban culture; (b) the modern architectural style in Singapore

The elaboration of the academic visits portray the knowledge exposure gained by the students from the local and oversea trips. The question is, how the trip experience relates to the accumulation of architectural knowledge? This has been answered by the student as below:

"Architecture is not merely related to buildings. The buildings will not exist if there is no exploration of the world.

The building design should respond sensitively towards the variety of context. For example, is it suitable to locate

Kuala Lumpur City Centre building within the village area?" (Respondent 1)

This shows that in order to design a building, architects need to see the diversity of context. The context includes the community way of life and the physical site itself. Though personal experience of a surrounding or an environment via academic trip is essential in having a better understanding of a context, the students acknowledge that it could also become costly. However, the data from the interview indicates that the students can still accept it as they realize that academic trip is one of the effective methods of learning architecture. Even though some students face the financial problem, they still admit on the benefits of executing the academic trips, and willing to spend money on that.

\section{Conclusion}

As a conclusion, the findings from the questionnaire survey and the in-depth interview show that the students perceive that the academic trip and site visit are beneficial for them especially in gaining architectural knowledge and exposure. Though majority of them admit that the site located outside the Klang Valley will incur extra cost and travelling time, but the knowledge and exposure gained is invaluable. They also believe that by travelling farther, more exposure and knowledge will be obtained compared to the project site located nearby. Therefore, it is suggested that the academic trip and site visit outside the context of university are encouraged in the architectural education. They should also remain as the important pedagogies in architectural education, especially the design studio subject. This is because they are able to provide invaluable exposure, knowledge and experience to the students, as understanding of various culture, tradition, environment and technology is vital for architecture students in designing buildings or spaces for the society.

The strategy of active involvement of the students, starting from the pre-trip stage, also provides many benefits to the development of the students. The students are able to learn and develop many soft-skills such as the leadership, communication and the teamwork skills. Hence, the field trip will not only provide knowledge related to the architecture field, but also the soft-skills that are beneficial for them. Moreover, the academic trip and site visit also encourage critical thinking for the students, where they learn, compare and analyze the information, knowledge and experience gained during the trip and visit. They may also inculcate awareness to the students on the value of culture and heritage in 
preserving one's identity. Moreover, they are also able to increase the students' interest in architecture, as the students manage to relate the theoretical aspects learnt in classroom to the real-life situation.

Therefore, from the findings, it is suggested that further action should be taken such as the provision of financial support to encourage the academic trip and site visit as the architectural design studio pedagogies. The financial support can be from many parties such as the university management, NGO and corporate bodies, and many others. Financial support is essential in encouraging farther location of the visit without burdening the students. Farther location of the visit provides more exposure to the students. Thus, it helps to produce graduate architects that are more sensitive towards the diversity of culture, heritage and built environment.

\section{Acknowledgement}

The authors would like to express great gratitude to Universiti Kebangsaan Malaysia and Ministry of Higher Education Malaysia for funding this study through research grant GGP-2017-046 and FRGS/1/2015/SSI11/UKM/02/2, respectively. The authors would also like to thank the student, Fara Alya, for the pictures contribution.

\section{References}

Abdullah, N. A. G., Beh, S. C., Tahir, M. M., Che Ani, A. I., \& Tawil, N. M. (2011). Architecture Design Studio Culture and Learning Spaces: A Holistic Approach to the Design and Planning of Learning Facilities. Procedia Social and Behavioral Sciences, 15, 27-32. doi: 10.1016/j.sbspro.2011.03.044

Alamoush, S. J., Jaafar, N. H., Husini, E. M., \& Ismail, W. N. W. (2018). Comfort Character of Landscape Features of Traditional Street in Amman, Jordan. Journal of the Malaysian Institute of Planners, 16 (1). 63-74. doi: 10.21837/pmjournal.v16.i5.411

Board of Architects Malaysia. (2013). Manual of Accreditation for Architecture Programme. Johor: Institute Sultan Iskandar of Urban Habitat and Highrise.

Board of Architects Malaysia. (2017). Deraf Akhir Dasar Senibina Identiti Kebangsaan. Unpublish Report.

Coughlin, P. K. (2010). Making Field Trips Count: Collaborating for Meaningful Experiences. The Social Studies, 101 (5). 200-210. doi: 10.1080/00377990903498431

Creswell, J. W. (2014). Research Design: Qualitative, Quantitative, and Mixed Methods Approaches (4 ${ }^{\text {th }}$ ed.). London: SAGE Publications.

Creswell, J. W., \& Creswell, J. D. (2018). Research Design: Qualitative, Quantitative and Mixed Methods Approaches $\left(5^{\text {th }}\right.$ ed.). London: SAGE Publications.

Danaci, H. M. (2015). Creativity and Knowledge in Architectural Education. Procedia Social and Behavioral Sciences, 174. 1309-1312. doi: 10.1016/j.sbspro.2015.01.752

Demirkaya, H., \& Atayeter, Y. (2011). A Study on the Experiences of University Lecturers and Students in the Geography field trip. Procedia Social and Behavioral Sciences, 19, 453-46. doi: 10.1016/j.sbspro.2011.05.154

Hope, M. (2009). The Importance of Direct Experience: A Philosophical Defence of Fieldwork in Human Geography. Journal of Geography in Higher Education, 33(2), 169-18. doi: 10.1080/03098260802276698

Ibrahim, N. L. N., \& Utaberta, N. (2012). Learning in Architecture Design Studio. Procedia Social and Behavioral Sciences, 60, 30-35. doi: 10.1016/j.sbspro.2012.09.342

Jaafar, N. H., \& Harun, N. Z. (2018). Building Opening Design Contributing to Traditional Streets' Walkability Character in Melaka Historical City. Journal of the Malaysian Institute of Planners, 16 (4). 188-198. doi: 10.21837/pmjournal.v16.i8.549

Joshi, A., Kale, S., Chandel, S., \& Pal, D. K. (2015). Likert Scale: Explored and Explained. British Journal of Applied Science \& Technology, 7 (4), 396-403.

Keumala, N., Younus, M. A., Kuan, Y., Razak, S., Ismail, M. A., \& Al-Obaidi, K. M. (2016). Pedagogy of Architectural Education on Sustainability in Malaysia - Student Perspective. Open House International, 41 (4). $104-108$.

Kurt, S. (2009). An Analytic Study on the Traditional Studio Environments and the Use of the Constructivist Studio in the Architectural Design Education. Procedia Social and Behavioral Sciences, 1, 401-408. doi: 10.1016/j.sbspro.2009.01.072

Leydon, J., \& Turner, S. (2013). The Challenges and Rewards of Introducing Field Trips into a Large Introductory Geography Class. Journal of Geography, 112 (6). 248-261. doi: 10.1080/00221341.2013.833279

Mahdavinejad, M., Shahrigharahkoshan, S., \& Ghasempourabadi, M. (2012). The Role of Site Analysis in Creativity of 
Students of Bachelor of Architecture, Case: Design Studio III. Procedia Social and Behavioral Sciences, 51, $1000-1004$. doi: 10.1016/j.sbspro.2012.08.277

McLoughlin, A. S. (2004). Engineering Active and Effective Field Trips. The Clearing House: A Journal of Educational Strategies, Issues and Ideas, 77 (4). 160-163. doi: 10.3200/TCHS.77.4.160-163

Nishio, K., \& Kashihara, A. (2016). Retrip: A Learning Environment for Augmenting and Pesenting Knowledge From Field Trip. Procedia Computer Science, 96, 1304-1313. doi: 10.1016/j.procs.2016.08.175

Sawyer, R. K. (2017). Teaching Creativity in Art and Design Studio Classes: A Systematic Literature Review. Educational Research Review, 22.99-113. doi: 10.1016/j.edurev.2017.07.002

Scott, C. M., \& Matthews, C. E. (2011). The "Science" Behind a Successful Field Trip to the Zoo. Science Activities, 48 (1). 29-38. doi: org/10.1080/00368121.2010.496814

Uzairiah, M. T. S. (2016). Qualitative Research, Interview Analysia \& Nvivo 11 exploration. Aras Publisher. 